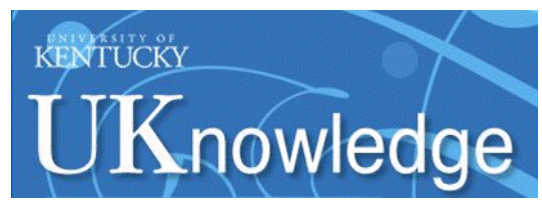

University of Kentucky

UKnowledge

Educational, School, and Counseling

Psychology Faculty Publications

Educational, School, and Counseling

Psychology

\title{
9-2017
}

\section{Pathway of Protection: Ethnic Identity, Self-Esteem, and Substance Use Among Multiracial Youth}

\author{
Sycarah Fisher \\ University of Kentucky, sycarah.fisher@uky.edu \\ Tamika C. B. Zapolski \\ Indiana University-Purdue University - Indianapolis \\ Chelsea Sheehan \\ University of Kentucky, cesh223@g.uky.edu \\ Jessica Barnes-Najor \\ Michigan State University
}

Follow this and additional works at: https://uknowledge.uky.edu/edp_facpub

Part of the Behavior and Behavior Mechanisms Commons, Race and Ethnicity Commons, Student

Counseling and Personnel Services Commons, and the Substance Abuse and Addiction Commons

Right click to open a feedback form in a new tab to let us know how this document benefits you.

\section{Repository Citation}

Fisher, Sycarah; Zapolski, Tamika C. B.; Sheehan, Chelsea; and Barnes-Najor, Jessica, "Pathway of Protection: Ethnic Identity, Self-Esteem, and Substance Use Among Multiracial Youth" (2017). Educational, School, and Counseling Psychology Faculty Publications. 26.

https://uknowledge.uky.edu/edp_facpub/26

This Article is brought to you for free and open access by the Educational, School, and Counseling Psychology at UKnowledge. It has been accepted for inclusion in Educational, School, and Counseling Psychology Faculty Publications by an authorized administrator of UKnowledge. For more information, please contact UKnowledge@lsv.uky.edu. 


\section{Pathway of Protection: Ethnic Identity, Self-Esteem, and Substance Use Among Multiracial Youth}

\section{Digital Object Identifier (DOI)}

https://doi.org/10.1016/j.addbeh.2017.03.003

\section{Notes/Citation Information}

Published in Addictive Behaviors, v. 72, p. 27-32.

(C) 2017 Published by Elsevier Ltd.

This manuscript version is made available under the CC-BY-NC-ND 4.0 license http://creativecommons.org/licenses/by-nc-nd/4.0/.

The document available for download is the author's post-peer-review final draft of the article. 
Published in final edited form as:

Addict Behav. 2017 September ; 72: 27-32. doi:10.1016/j.addbeh.2017.03.003.

\title{
Pathway of Protection: Ethnic Identity, Self-Esteem, and Substance Use among Multiracial Youth
}

\author{
Sycarah Fisher, PhD, \\ University of Kentucky \\ Tamika C. B. Zapolski, PhD, \\ Indiana University Purdue University - Indianapolis \\ Chelsea Sheehan, M.A., and \\ University of Kentucky \\ Jessica Barnes-Najor, Ph.D. \\ Community Outreach and Engagement, Michigan State University
}

\begin{abstract}
Fifty percent of adolescents have tried an illicit drug and $70 \%$ have tried alcohol by the end of high school, with even higher rates among multiracial youth. Ethnic identity is a protective factor against substance use for minority groups. However, little is known about the mechanisms that facilitate its protective effects, and even less is known about this relationship for multiracial youth. The purpose of the present study was to examine the protective effect of ethnic identity on substance use and to determine whether this relationship operated indirectly through self-esteem, a strong predictor of substance use for among adolescent populations. Participants included 468 multiracial youth in grades six through 12 (53\% female). The results found that ethnic identity was indeed related to substance use, partially through changes in self-esteem. Findings from this study contribute to our understanding and development of models of risk and protection for an understudied population.
\end{abstract}

\section{Keywords}

Ethnic Identity; Multiracial adolescents; Self-Esteem; Substance Use

\begin{abstract}
Adolescents continue to use substances at alarming rates. By the end of high school, $70 \%$ of students have tried alcohol and 50\% have tried an illicit substance (NIDA, 2014). Rates are even more dire for multiracial youth, with researchers finding that multiracial youth are more likely to use substances than other monoracial groups (Choi et al., 2006; Jackson and LeCroy, 2009; Udry, Li, \& Hendrickson-Smith, 2003), with rates of current illicit substance use at $17.4 \%$ compared to $8.8 \%$ for Latinos, $9.5 \%$ for Whites, and $10.5 \%$ among Blacks (SAMHSA, 2013). Such use is of concern given the associated health outcomes, including school dropout (Orpinas, Lacy, Nahapetyan, Dube \& Song, 2015), involvement in the
\end{abstract}

Correspondence concerning this article should be addressed to Sycarah Fisher, Department of Educational, School, and Counseling Psychology, The University of Kentucky, Lexington, KY 40509. Sycarah.fisher@uky.edu. 
juvenile justice system (Monahan, Rhew, Hawkins, \& Brown, 2014) and suicide (Wong, Zhou, Goebert, \& Hishinuma, 2013). Further, the initiation of substance use during adolescence (before age 14) is associated with substance use dependence after age 18 (SAMHSA, 2013). Therefore, it is imperative to identify factors associated with lower substance use during adolescence. Ethnic identity is one such factor that has been found to be protective against substance use among monoracial youth (Stock et al., 2013; Schwartz, Zamboanga, Luyckx, Meca, \& Ritchie, 2013). Despite this fact, little research has investigated the mechanisms by which ethnic identity lowers substance use. The present study will investigate whether ethnic identity is related to lower levels of substance abuse among multiracial youth and if that relationship is mediated by self-esteem, a wellestablished protective factor for adolescent health outcomes.

\section{Ethnic Identity and Substance Use}

Ethnic identity is the "expression of loyalty, commitment, and belongingness towards one's own ethnic group which is produced by the exploration, resolution, and affirmation of one's ethnicity" (Bernal, Knight, Ocampo, Garza, \& Cota, 1993). Although there are many different definitions of ethnic identity in the literature, most authors agree that ethnic identity becomes more solidified as children get older and that adolescence is a critical period in which this identity develops (Phinney, 1990; Quintana et al, 2006; Yip, Seaton, and Sellers, 2006).

Ethnic identity has shown to reduce risk for negative health outcomes among minority youth, such as substance use (Stock et al., 2013; Schwartz, Zamboanga, Luyckx, Meca, \& Ritchie, 2013). Current conceptualizations around the relationship between ethnic identity and substance use center around the notion that individuals with a maladaptive identity engage in riskier behavior. The most robust effect has been observed for African American youth, with higher levels of ethnic identity associated with lower substance use (Rivas-Drake et al., 2014; Marsiglia, Kulis, \& Hecht, 2001; Brook \& Pahl, 2005; Pugh \& Bry, 2007; Richman, Boynton, Costanzo, \& Banas, 2013). Findings are mixed for individuals of Latino decent. Some studies find a protective effect (Richman et al., 2013; Kulis, Marsiglia, Kopak, Olmsted, \& Crossman, 2012), while others find that higher levels of ethnic identity lead to higher levels of substance use (Zamboanga, Schwartz, Jarvis, \& Van Tyne, 2009). Mixed findings among Latino youth may be due to the heterogeneity of backgrounds comprised within the label of "Latino," such that Latino populations are almost exclusively lumped into one pan-ethnic category, although evidence suggests differences in both the prevalence of substance use (Carlton-Smith \& Skeer, 2015; Unger, Thing, Soto, \& Baezconde-Garbanati, 2014) and level of acculturation and ethnic identity (Carlton-Smith \& Skeer, 2015; Choi, Sakamoto, \& Powers, 2008; Guilamo-Ramos, Jaccard, Johansson, \& Turrisi, 2004) between Latino subgroups.

Interestingly, although multiracial youth represent the fastest growing youth population in the United States (Jones \& Bullock, 2012; McCubbin, 2013), research on the relationship of multiracial ethnic identity and substance use is scant. The limited research that has been conducted is mixed with some finding that ethnic identity is protective against substance use (e.g., Choi, Harachi, Gillmore and Catalano, 2006; AUTHORS, IN PRESS) for multiracial 
youth and others finding no relationship (e.g., James, Kim and Armijo, 2000; Marsiglia, Kulis, \& Hecht, 2001). Some researchers have speculated that because of diverging backgrounds, ethnic identity may be more challenging to achieve for multiracial youth than monoracial youth and may result in more risk-taking behavior and higher levels of psychological distress (Fisher, Reynolds, Hsu, Barnes \& Tyler, 2014; Gibbs \& MoskowitzSweet, 1991; Coleman \& Carter, 2007; Lusk, Taylor, Nanney, \& Austin, 2010; Udry, Li, \& Hendrickson-Smith, 2003). Yet, others find that having more than one ethnicity does not have an impact on identity development and subsequent behaviors (Kato, 2000). Therefore, additional work is needed to understand the complex relationships between ethnic identity and substance use outcomes for multiracial youth.

\section{Ethnic Identity, Self-Esteem, and Substance Use}

While the research on the relationship between ethnic identity and substance use for multiracial youth is limited with mixed findings, the mechanisms related to this relationship are unknown (Neblett, Rivas-Drake, Umana-Taylor, 2012). One study conducted by AUTHORS and colleagues (IN PRESS) attempted to identify potential mechanisms by looking at attitudes towards substances as a potential mediator between ethnic identity and substance use. While this relationship was significant for other racial groups (i.e. African American and Latino), it was not significant for multiracial youth, indicating that ethnic identity does not operate through cognitive factors such as attitudes towards substances. Therefore, it is imperative to investigate other mechanisms that may mediate this relationship.

One potential mechanism is through the increase of self-esteem. This hypothesis is based on literature documenting a strong positive relationship between low self-esteem and risky behavior among adolescent and young adult populations (Tevendale et al., 2009), as well as a positive relationship between ethnic identity and self-esteem (Carlson, Uppal \& Prosser, 2000; Kiang, Yip, Gonzales-Backen, Witkow \& Fuligni, 2006; Phinney, 1990; Phinney, Cantu \& Kurtz, 1997; Pyant, \& Yanico, 1991). For example, several studies have found that adolescents from varying ethnic backgrounds with lower self-esteem report more substance use (Bitancourt, Tissot, Fidalgo, Galduroz, \& Filho, 2016; Torres \& Fernandez, 1995; Tiggemann, 2005; Wu, Wong, Shek, \& Loke, 2014). Further, the positive relationship between ethnic identity and self-esteem has been long identified in the literature, particularly among African American youth (Wallace \& Fisher, 2007; Belgrave, Brome, \& Hampton, 2000; Burlew et al., 2000; Corneille \& Belgrave, 2007; Townsend \& Belgrave, 2000; RivasDrake et al., 2014). This relationship has also been found across various ethnic groups (Phinney, 1996; Sellers, Copeland-Linder, Martin, \& Lewis, 2006; Umana-Taylor, Diversi \& Fine, 2002). Given the positive association between ethnic identity and self-esteem, as well as between self-esteem and substance use, it is plausible that ethnic identity may influence risk for substance use indirectly through self-esteem.

\section{Current Study and Hypotheses}

To our knowledge, limited work has been conducted examining the direct relationship between ethnic identity and substance use among multiracial youth, with no study, to date, 
examining a path model between ethnic identity, self-esteem, and substance use for multiracial youth. The purpose of the present study is to fill this important gap in the literature by investigating the relationship between ethnic identity and substance use in a sample of multiracial youth. Additionally, the study will determine if the path model operates indirectly through self esteem. This study contributes significantly to the literature by examining mechanisms of protection for substance use in an understudied population that exhibits higher rates of substance use than other ethnic groups (Choi et al., 2006; Jackson and LeCroy, 2009; Udry, Li, \& Hendrickson-Smith, 2003). Our hypotheses controlling for age and gender, are: 1) higher ethnic identity will predict lower substance use; 2) higher ethnic identity will predict higher self-esteem; 3) the pathway between higher ethnic identity and lower substance use will operate indirectly through increasing self-esteem.

\section{Methods}

\section{Participants and Procedures}

The current study involves participants drawn from a larger study examining school and health behavior outcomes among students between fourth and twelfth grade. As approved by the University IRB, participants were sampled from 159 schools (21 school districts) in a large Midwestern county. Informed consent forms were sent home to parents of potential participants. Signed consent forms were obtained from 50\% of parents (approximately 12,000 each year). Retention rates for waves 2 through 5 were modest with less than onethird of the participants (27.7\%) completing two waves of data (see Barnes, Almerigi \& Hsu, 2009, for further information about the parent study). For the current study, all participants who provided data at the final data collection, wave 5, were included in the study. Wave 5 was chosen due to a high completion rate of study variables of interest and high number of multiracial participants, with a sample size of 468 youth. It should be noted that this sample is not generalizable to the general population due to the collection of data in one geographic location. Participants were equally divided based on gender (53\% female), and the on average the students were in eighth grade $(S D=1.96)$.

\section{Measures}

Demographic Information-Participants were asked to indicate their gender, grade, birthdate, and racial/ethnic background (i.e., African American, Native American, Asian, Latino, Multiracial, White, and Other). Those participants that identified as Multiracial were included in the study. Participants who selected Multiracial are considered to identify as multiracial rather than the race of any particular group, as they opted to endorse multiracial rather than a singular race category. The Multiracial category also did not ask participants to specify the race of their parents, thus subgroups of multiracial youth could not be constructed.

Ethnic Identity-The Multi-group Ethnic Identity Measure (MEIM, Roberts et al., 1999) was used as a measure of ethnic identity that could be utilized across racial/ethnic groups (i.e. African American, Asian American, European American, Latino, Native American, and multiracial). Further, use of the MEIM with multiracial populations has been well documented (Bracey et al., 2004; Fisher et al, 2014; Huang, 2011; Spencer, 2000). The 
MEIM is a 12-item scale designed to measure two components of ethnic identity: exploration and affirmation. For the exploration subscale, items included "In order to learn more about my ethnic background" and "I have often talked to other people about my ethnic group." For the affirmation subscale, items included "I feel good about my cultural or ethnic background." Items were rated on a 4-point Likert scale, with responses ranging from 1 (strongly disagree) to 4 (strongly agree). The total MEIM scale was used for the current study and had high internal consistency $(a=0.91)$, which is consistent with previous literature with reliability ranging from $0.81-0.92$ (Ponterotto, Gretchen, Utsey, Stracuzzi, \& Saya, 2003).

Self Esteem-The self-esteem measure was adapted from items included in various national studies conducted among youth (e.g., Monitoring the Future, YRBSS). Participants were asked to respond to a number of questions on a 4-point likert scale ( $1=$ strongly disagree to 4 = strongly agree). Items include questions such as "I think I am good looking" and "I like who I am."

Substance Use-The drug use measure was also adapted from items included in various national studies conducted among youth (e.g., Monitoring the Future, YRBSS). Participants were asked to indicate how many days in the past 30 days had they had used marijuana, cigarettes, half a pack or more cigarettes, smokeless tobacco, inhalants, other drugs, had one drink of alcohol, or had 5 drinks of alcohol. Responses choices were provided on a 7-point Likert scale, with 1 (0-days), 2 ( 1 or 2 days), 3 (3-5 days), 4 (6-9 days), 5 (10-19 days), 6 (20-29 days) and 7 (everyday). Responses were dichotomized into drug use and non-use categories.

\section{Data Analyses}

All analyses were performed using SPSS 24. While students are nested within schools, preliminary analyses revealed no significant contribution by school, with interclass correlations ranging from 0.023 for ethnic identity to 0.028 for self-esteem and substance. Thus, analyses were analyzed at the individual level. However, gender and grade were included as covariates in our analysis, as consistent with previous literature, drug use was higher for males (Chen \& Jacobson, 2012) and significantly increased with age (NIDA, 2014).

Path analyses were performed using the PROCESS macro (Hayes, 2013) to explore the relationship between ethnic identity and substance use, with self-esteem as the mediator (Model 4 specified by Hayes, 2013). This analysis was run controlling for grade and gender. The PROCESS macro provides estimates for each path within the mediation model, thus provides estimates on the effect of ethnic identity on self-esteem, as well as the effect of self-esteem on substance use. Additionally estimates are provided for the total and direct effect of the independent variable on the dependent variable and indirect effect of the independent variable through the mediator. The PROCESS macro uses bootstrapping to generate bias-corrected confidence intervals for the indirect effect and various indices of effect size for the indirect effect (Hayes, 2013). For all mediation analyses in the current 
study, we used 5,000 bootstrap samples. Only participants who provided complete data were included in current study, thus no imputation of missing data was required.

\section{Results}

Descriptive statistics are presented in Table 1. A correlation matrix was constructed to assess the association between the study variables (Table 2). Because gender is dichotomous, correlations between these two variables are point-biseral coefficients, and correlations among other variables are Spearman correlations. Ethnic Identity was significantly negatively correlated with substance use $(r=-.224, \mathrm{p}<.01)$ and significantly positively correlated with self-esteem $(r=.310, \mathrm{p}<.01)$. Self-Esteem was significantly negatively correlated with substance use $(\mathrm{r}=-.155, \mathrm{p}<.01)$. Grade differences were observed. Older youth reported greater substance use $(\mathrm{r}=0.293, p<.01)$ and lower ethnic identity than younger participants $(\mathrm{r}=-.220, p<.01)$.

\section{Path Model: Ethnic Identity, Self-Esteem, and Substance Use}

A path model was estimated to test the hypothesized direct protective effect of ethnic identity on past-month drug use and whether the pathway operated indirectly through selfesteem. Given the significant correlation between gender and grade on drug use, they were controlled for within the path models. Findings indicated that higher ethnic identity was associated with lower drug use $(b=-.028, \mathrm{p}<.05)$. The pathways between ethnic identity and self-esteem $(b=.156, p<.001)$, and between self-esteem and drug use (effect estimate= $-.066, \mathrm{p}=.01$ ) were also significant, indicating that higher ethnic identity was associated with higher self-esteem and higher self-esteem was protective against drug use. When assessing the total indirect path model including self-esteem, the protective effect ethnic identity on past month drug use through self-esteem was significant (point estimate of indirect effect $=-.010,95 \%$ Boot $\mathrm{CI}=-.021,-.003$ ) youth. The direct effect between ethnic identity and drug use became non-significant once accounting for the indirect effect of selfesteem (point direct effect estimate $=-.0185 \mathrm{p}=.181$ ). See Table 3 and Figure 1 for all path coefficients.

\section{Discussion}

Multiracial individuals are the fastest growing population in the United States (U.S. Census Bureau, 2012), and have one of the highest rates of substance use (SAMHSA, 2013; Choi et al., 2006; Jackson and LeCroy, 2009; Udry, Li, \& Hendrickson-Smith, 2003). Despite this fact, little research exists on factors related to their substance use and potential protective mechanisms. The purpose of the present study was to investigate the relationship between ethnic identity and substance use for multiracial youth and the indirect effect of self-esteem within the protective pathway.

The present study found that ethnic identity was indeed protective against substance use among our sample of multiracial youth. This indicates that the higher the ethnic identity, the less substances adolescents reported using. This finding supports the notion that ethnic identity is an important part of development that is related to positive health outcomes among adolescents (AUTHORS, IN PRESS). While ethnic identity was indeed protective for 
multiracial youth, it decreased as students got older contrary to research on other ethnic groups. Literature on identity development models for multiracial youth suggest that identity development for this group may not be as linear as it is for others as they integrate their various ethnic backgrounds into one ethnic classification (Amiot, Sablonniere, Terry, \& Smith, 2007; Gonzales-Bracken, 2013). Moreover, while some research indicates that ethnic identity may be more difficult for multiracial youth to achieve due to their divergent backgrounds, the findings of the present study underscore how important it is for this group to reach an achieved identity. Given that multiracial youth can identify themselves as multiracial or separately identify themselves as one of many racial/ethnic backgrounds, more work is needed to untangle these processes (Clark, Doyle, \& Clincy, 2013).

Social Identity theory posits that the positive sense of belonging to one's group contributes to positive self-esteem (Crocker, Luhtanen, Blaine, \& Broadnax, 1994; Phinney, Cantu \& Kurtz, 1997). Our findings support this theory, with self-esteem positively associated with ethnic identity and operating indirectly between ethnic identity and substance use. This is significant, as a previous study on the relationship between ethnic identity and substance use did not find an indirect path through substance use attitudes for multiracial youth, though this pathway was observed with other racial/ethnic groups (AUTHORS, IN PRESS). Thus, our findings suggest that although the pathway to protection for multiracial youth may not operate through cognition for multiracial youth as it does with other ethnic groups, it does appear to operate through developing a strong sense of self. It may be that self-esteem is a more predictive mediator between ethnic identity and substance abuse than cognitive factors because of the nature of ethnic identity development in multiracial youth; the process of exploring and coming to terms with and accepting two separate identities. Self-esteem is conceptualized as an individuals' positive or negative view of themselves (Orth \& Robins, 2014). Thus, multiracial youth who have navigated this identity formation successfully, a process researchers assert may be more contentious than other racial groups (GonzalesBraken, 2013), have more positive views of themselves and limit their use of substances.

\section{Limitations and Future Directions}

While this study contributes significantly to the literature by investigating mechanisms of protection in an understudied population of high-risk substance users, several limitations should be noted. First, the study was conducted with a sample limited to the Midwest and is not generalizable to other groups. Second, due to our sampling techniques, the sample consists of multiracial youth that identify as multiracial, without considering nuanced differences between combinations of ethnicities. There has been considerable debate in the literature about how to identify multiracial youth (Brittian et al., 2013). However, research has found that this method of identification is acceptable for the variables of interest including ethnic identity and self-esteem. Specifically, research comparing the ethnic identity and self-esteem scores of Asian/White, Black/White, Latino/White, Asian/Black, Asian/Latino, and Black/Latino found no significant differences (Bracey et al., 2004). Second, the sample for this study consisted of self-identified multiracial youth, a population found to have higher rates of self-esteem than multiracial youth who identify with only one part of their identity (Binning, Unzueta, Huo, \& Molina, 2009). Further, while several researchers have conducted research with multiracial youth finding no differences in 
subgroups (Bracey, Bámaca, \& Umana-Taylor, 2004), multiracial youth are a heterogeneous group. Therefore, future research should identify if there are differences in these relationships based on the ethnic makeup of the individual.

\section{Conclusion}

The current study extends the literature by looking at protective mechanisms related to substance use in an understudied population of multiracial adolescents. The results indicated that ethnic identity was indeed protective against substance use, partially through changes in self-esteem. While additional research is needed, these results indicate that interventionists should incorporate factors related to ethnic identity and psychological factors such as selfesteem into their intervention efforts.

\section{Acknowledgments}

This research was supported by NIH award DA05312 to Sycarah Fisher and NIH award KL2TR001106 to Tamika Zapolski.

\section{References}

Amiot CE, De la Sablonniere R, Terry DJ, Smith JR. Integration of social identities in the self: Toward a cognitive-developmental model. Personality and Social Psychology Review. 2007; 11(4):364-388. [PubMed: 18453468]

AUTHORS. Examining the protective effect of ethnic identity on drug attitudes and use among a diverse youth population. Journal of Youth and Adolescence. in press.

Barnes, J., Almerigi, J., Hsu, WW. Coordinated Community Assessment: Data from the Coordinated Community Student Survey. 2009. Retrieved from http://cerc.msu.edu/research/pastprojects.aspx

Belgrave F, Brome D, Hampton C. The contribution of Afrocentric values and racial identity to the prediction of drug knowledge, attitudes and use among African American youth. Journal of Black Psychology. 2000; 26:386-401.

Bernal ME, Knight GP, Ocampo KA, Garza CA, Cota MK. Development of Mexican American identity. Ethnic identity: Formation and transmission among Hispanics and other minorities. 1993:31-46.

Binning KR, Unzueta MM, Huo YJ, Molina LE. The interpretation of multiracial status and its relation to social engagement and psychological well-being. Journal of Social Issues. 2009; 65(1):35-49.

Bitancourt T, Tissot MCRG, Fidalgo TM, Galduróz JCF, da Silveira Filho DX. Factors associated with illicit drugs' lifetime and frequent/heavy use among students results from a population survey. Psychiatry research. 2016; 237:290-295. [PubMed: 26832836]

Bracey JR, Bámaca MY, Umana-Taylor AJ. Examining ethnic identity and self-esteem among biracial and monoracial adolescents. Journal of Youth and Adolescence. 2004; 33(2):123-132. DOI: 10.1023/B:JOYO.0000013424.93635.68

Brook JS, Pahl K. The protective role of ethnic and racial identity and aspects of an Africentric orientation against drug use among African American young adults. The Journal of genetic psychology. 2005; 166(3):329-345. [PubMed: 16173675]

Burlew K, Neely D, Johnson C, Hucks TC, Purnell B, Butler J, ... Burlew R. Drug attitudes, racial identity, and alcohol use among African American adolescents. Journal of Black Psychology. 2000; 26(4):402-420. DOI: 10.1177/0095798400026004004

Carlson C, Uppal S, Prosser EC. Ethnic differences in processes contributing to the self-esteem of early adolescent girls. The Journal of Early Adolescence. 2000; 20(1):44-67.

Carlton-Smith AR, Skeer MR. Differences in adolescent substance use by Hispanic subgroup: What we know and what we need to find out. Journal of Ethnicity In Substance Abuse. 2015; 14(4):340350. DOI: 10.1080/15332640.2014.990073 [PubMed: 26213214] 
Chen P, Jacobson KC. Developmental trajectories of substance use from early adolescence to young adulthood: gender and racial/ethnic differences. Journal of Adolescent Health. 2012; 50(2):154163. [PubMed: 22265111]

Choi Y, Harachi TW, Gillmore MR, Catalano RF. Are multiracial adolescents at greater risk? Comparisons of rates, patterns, and correlates of substance use and violence between monoracial and multiracial adolescents. American Journal of Orthopsychiatry. 2006; 76(1):86. [PubMed: 16569131]

Choi KH, Sakamoto A, Powers D. Who is hispanic? Hispanic identity among African Americans, Asian Americans, others, and whites. Sociological Inquiry. 2008; 78(3):335-371.

Clark TT, Doyle O, Clincy A. Age of first cigarette, alcohol, and marijuana use among US biracial/ ethnic youth: A population-based study. Addictive behaviors. 2013; 38(9):2450-2454. [PubMed: 23688908]

Coleman VH, Carter MM. Biracial self-identification: Impact on trait anxiety, social anxiety, and depression. Identity: An International Journal of Theory and Research. 2007; 7:103-114. DOI: 10.1080/15283480701326018

Corneille MA, Belgrave FZ. Ethnic identity, neighborhood risk, and adolescent drug and sex attitudes and refusal efficacy: The urban African American girls' experience. Journal of Drug Education. 2007; 37(2):177-190. DOI: 10.2190/UJ17-34J7-U306-2822 [PubMed: 17977240]

Crocker J, Luhtanen R, Blaine B, Broadnax S. Collective self-esteem and psychological well-being among White, Black, and Asian college students. Personality and social psychology Bulletin. 1994; 20(5):503-513.

Fisher S, Reynolds JL, Hsu WW, Barnes J, Tyler K. Examining multiracial youth in context: Ethnic identity development and mental health outcomes. Journal of Youth and Adolescence. 2014; 43(10):1688-1699. [PubMed: 25100614]

Gibbs JT, Moskowitz-Sweet G. Clinical and cultural issues in the treatment of biracial and bicultural adolescents. Families in Society. 1991; 72(10):579-592.

Gonzales-Backen MA. An application of ecological theory to ethnic identity formation among biethnic adolescents. Family Relations. 2013; 62(1):92-108.

Guilamo-Ramos V, Jaccard J, Johansson M, Turrisi R. Binge Drinking Among Latino Youth: Role of Acculturation-Related Variables. Psychology of Addictive Behaviors. 2004; 18(2):135-142. DOI: 10.1037/0893-164X.18.2.135 [PubMed: 15238055]

Hayes, AF. Introduction to mediation, moderation, and conditional process analysis: A regressionbased approach. Guilford Press; 2013.

Huang CY, Stormshak EA. A longitudinal examination of early adolescence ethnic identity trajectories. Cultural Diversity and Ethnic Minority Psychology. 2011; 17(3):261. [PubMed: 21787058]

Jackson KF, Lecroy CW. The influence of race and ethnicity on substance use and negative activity involvement among monoracial and multiracial adolescents of the southwest. Journal of Drug Education. 2009; 39(2):195-210. [PubMed: 19999705]

James WH, Kim GK, Armijo E. The influence of ethnic identity on drug use among ethnic minority adolescents. Journal of Drug Education. 2000; 30(3):265-280. [PubMed: 11092148]

Jones, NA., Bullock, J. The two or more races population: 2010; United States Census Bureau, C2010BR-13. 2012. p. 1-24.Retrieved from https://www.census.gov/prod/cen2010/briefs/ c2010br-13.pdf

Kiang L, Yip T, Gonzales-Backen M, Witkow M, Fuligni AJ. Ethnic identity and the daily psychological well-being of adolescents from Mexican and Chinese backgrounds. Child Development. 2006; 77:1338-1350. DOI: 10.1111/j.1467-8624.2006.00938.x [PubMed: 16999802]

Kulis SS, Marsiglia FF, Kopak AM, Olmsted ME, Crossman A. Ethnic Identity and Substance Use Among Mexican-Heritage Preadolescents Moderator Effects of Gender and Time in the United States. The Journal of early adolescence. 2012; 32(2):165-199. [PubMed: 22790485]

Quintana SM, Aboud FE, Chao RK, Contreras-Grau J, Cross WE, Hudley C, Hughes D, Liben LS, Nelson-Le Gall S, Vietze DL. Race, ethnicity, and culture in child development: Contemporary 
research and future directions. Child Development. 2006; 77:1129-1141. DOI: 10.1111/j. 1467-8624.2006.00951.x [PubMed: 16999787]

Lusk EM, Taylor MJ, Nanney JT, Austin CC. Biracial identity and its relation to self-esteem and depression in mixed Black/White biracial individuals. Journal of Ethnic \& Cultural Diversity in Social Work. 2010; 19(2):109-126.

Marsiglia FF, Kulis S, Hecht ML, Sills S. Ethnicity and ethnic identity as predictors of drug norms and drug use among preadolescents in the US Southwest. Substance Use \& Misuse. 2004; 39:10611094. [PubMed: 15387204]

McCubbin, L. Acknowledging the growing population of multiracial youth and families. APA Children, Youth, and Families. 2013. Retrieved from http://www.apa.org/pi/families/resources/ newsletter/2013/08/multiracial-population.aspx

Monahan KC, Rhew IC, Hawkins JD, Brown EC. Adolescent Pathways to Co-Occurring Problem Behavior: The Effects of Peer Delinquency and Peer Substance Use. Journal of research on adolescence. 2014; 24(4):630-645. [PubMed: 25506186]

National Institute on Drug Abuse [NIDA]. Monitoring the Future Study: Trends in the prevalence of various drugs. 2014. Retrieved from http://www.drugabuse.gov/trends-statistics/monitoringfuture/ monitoring-future-study-trends-in-prevalence-various-drugs

Neblett EW, Rivas-Drake D, Umaña-Taylor AJ. The promise of racial and ethnic protective factors in promoting ethnic minority youth development. Child Development Perspectives. 2012; 6(3):295303.

Orpinas P, Lacy B, Nahapetyan L, Dube SR, Song X. Cigarette smoking trajectories from sixth to twelfth grade: associated substance use and high school dropout. Nicotine \& Tobacco Research. 2015:ntv040.

Orth U, Robins RW. The development of self-esteem. Current Directions in Psychological Science. 2014; 23(5):381-387.

Phinney JS. Ethnic identity in adolescents and adults: Review of research. Psychological Bulletin. 1990; 108:499-514. DOI: 10.1037/0033-2909.108.3.499 [PubMed: 2270238]

Phinney JS. When we talk about American ethnic groups, what do we mean? American Psychologist. 1996; 51(9):918.

Phinney JS, Cantu CL, Kurtz DA. Ethnic and American identity as predictors of self-esteem among African American, Latino, and White adolescents. Journal of Youth and adolescence. 1997; 26(2): $165-185$.

Ponterotto JG, Gretchen D, Utsey SO, Stracuzzi T, Saya R. The multigroup ethnic identity measure (MEIM): Psychometric review and further validity testing. Educational and Psychological Measurement. 2003; 63(3):502-515. DOI: 10.1177/0013164403063003010

Pugh LA, Bry BH. The protective effects of ethnic identity for alcohol and marijuana use among Black young adults. Cultural Diversity and Ethnic Minority Psychology. 2007; 13(2):187. [PubMed: 17500608]

Pyant CT, Yanico BJ. Relationship of racial identity and gender-role attitudes to Black women's psychological well-being. Journal of Counseling Psychology. 1991; 38(3):315.

Richman LS, Boynton MH, Costanzo P, Banas K. Interactive effects of discrimination and racial identity on alcohol-related thoughts and use. Basic And Applied Social Psychology. 2013; 35(4): 396-407. DOI: 10.1080/01973533.2013.803966

Rivas-Drake D, Seaton EK, Markstrom C, Quintana S, Syed M, Lee RM, ... Yip T. Ethnic and racial identity in adolescence: Implications for psychosocial, academic, and health outcomes. Child Development. 2014; 85(1):40-57. DOI: 10.1111/cdev.12200 [PubMed: 24490891]

Roberts RE, Phinney JS, Masse LC, Chen YR, Roberts CR, Romero A. The structure of ethnic identity of young adolescents from diverse ethnocultural groups. The Journal of Early Adolescence. 1999; 19:301-322. DOI: 10.1177/0272431699019003001

Schwartz SJ, Zamboanga BL, Luyckx K, Meca A, Ritchie RA. Identity in emerging adulthood reviewing the field and looking forward. Emerging Adulthood. 2013; 1(2):96-113.

Sellers RM, Copeland-Linder N, Martin PP, Lewis RH. Racial identity matters: The relationship between racial discrimination and psychological functioning in African American adolescents. Journal of Research on Adolescence. 2006; 16(2):187-216. 
Spencer MS, Icard LD, Harachi TW, Catalano RF, Oxford M. Ethnic identity among monoracial and multiracial early adolescents. The Journal of Early Adolescence. 2000; 20(4):365-387.

Stock ML, Gibbons FX, Gerrard M, Houlihan AE, Weng CY, Lorenz FO, Simons RL. Racial identification, racial composition, and substance use vulnerability among African American adolescents and young adults. Health Psychology. 2013; 32(3):237-247. [PubMed: 23088177]

Substance Abuse and Mental Health Services Administration. Results from the 2012 National Survey on Drug Use and Health: Summary of National Findings. Rockville, MD: Substance Abuse and Mental Health Services Administration; 2013. NSDUH Series H-46, HHS Publication No. (SMA) $13-4795$

Tevendale HD, Lightfoot M, Slocum SL. Individual and environmental protective factors for risky sexual behavior among homeless youth: an exploration of gender differences. AIDS and Behavior. 2009; 13(1):154-164. [PubMed: 18535902]

Tiggemann M. Body dissatisfaction and adolescent self-esteem: Prospective findings. Body image. 2005; 2(2):129-135. [PubMed: 18089181]

Torres R, Fernández F. Self-esteem and value of health as determinants of adolescent health behavior. Journal of Adolescent Health. 1995; 16(1):60-63. [PubMed: 7742341]

Townsend TG, Belgrave FZ. The impact of personal identity and racial identity on drug attitudes and use among African American children. Journal of Black Psychology. 2000; 26(4):421-436. DOI: 10.1177/0095798400026004005

Udry JR, Li RM, Hendrickson-Smith J. Health and behavior risks of adolescents with mixed-race identity. Journal Information. 2003; 93(11):1865-1870. DOI: 10.2105/AJPH.93.11.1865

Umaña-Taylor AJ, Diversi M, Fine MA. Ethnic identity and self-esteem of Latino adolescents distinctions among the Latino populations. Journal of Adolescent Research. 2002; 17(3):303-327.

Unger JB, Thing J, Soto DW, Baezconde-Garbanati L. Associations Between Ethnic Labels and Substance Use Among Hispanic/Latino Adolescents in Los Angeles. Substance Use \& Misuse. 2014; 49(8):1007-1016. [PubMed: 24779500]

U.S. Census Bureau. US Census shows multiple-race population grew faster than single race population. 2012. Retrieved from https://www.census.gov/newsroom/releases/archives/race/ cb12-182.html

Wallace SA, Fisher CB. Substance use attitudes among urban black adolescents: The role of parent, peer, and cultural factors. Journal of Youth and Adolescence. 2007; 36(4):441-451.

Wong SS, Zhou B, Goebert D, Hishinuma ES. The risk of adolescent suicide across patterns of drug use: a nationally representative study of high school students in the United States from 1999 to 2009. Social psychiatry and psychiatric epidemiology. 2013; 48(10):1611-1620. [PubMed: 23744443]

Wu CS, Wong HT, Shek CH, Loke AY. Multi-dimensional self-esteem and substance use among Chinese adolescents. Substance abuse treatment, prevention, and policy. 2014; 9(1):1-8.

Yip T, Seaton EK, Sellers RM. African American racial identity across the lifespan: Identity status, identity content, and depressive symptoms. Child Development. 2006; 77:1504-1517. DOI: 10.1111/j.1467-8624.2006.00950.x [PubMed: 16999814]

Zamboanga BL, Schwartz SJ, Jarvis LH, Van Tyne K. Acculturation and substance use among Hispanic early adolescents: Investigating the mediating roles of acculturative stress and selfesteem. The Journal of Primary Prevention. 2009; 30(3-4):315-333. [PubMed: 19408121] 


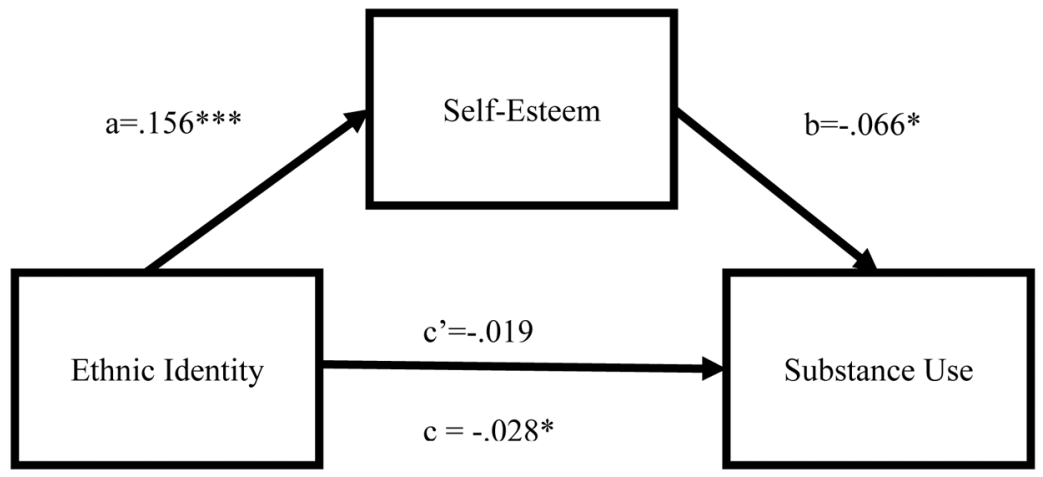

Figure 1.

Depiction of structural model representing the pathways to substance use for multiracial youth based on levels of ethnic identity and self-esteem. Only hypothesized pathways are presented. Not included in the figure, for ease of presentation, are disturbance terms and error terms. $* \mathrm{p}<.05, * * * \mathrm{p}<.001$. 
Table 1

Percentages (n) and Means (S.Es.) for Multiracial Participants

\begin{tabular}{lcc}
\hline & Male & Female \\
\hline Substance Use & $29.6(63)$ & $28.6(73)$ \\
Ethnic Identity (high=good) & $2.55(0.070)$ & $2.67(0.059)$ \\
Self-Esteem (high=good) & $3.320(0.033)$ & $3.27(0.032)$ \\
\hline
\end{tabular}




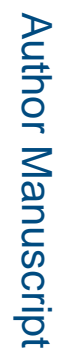
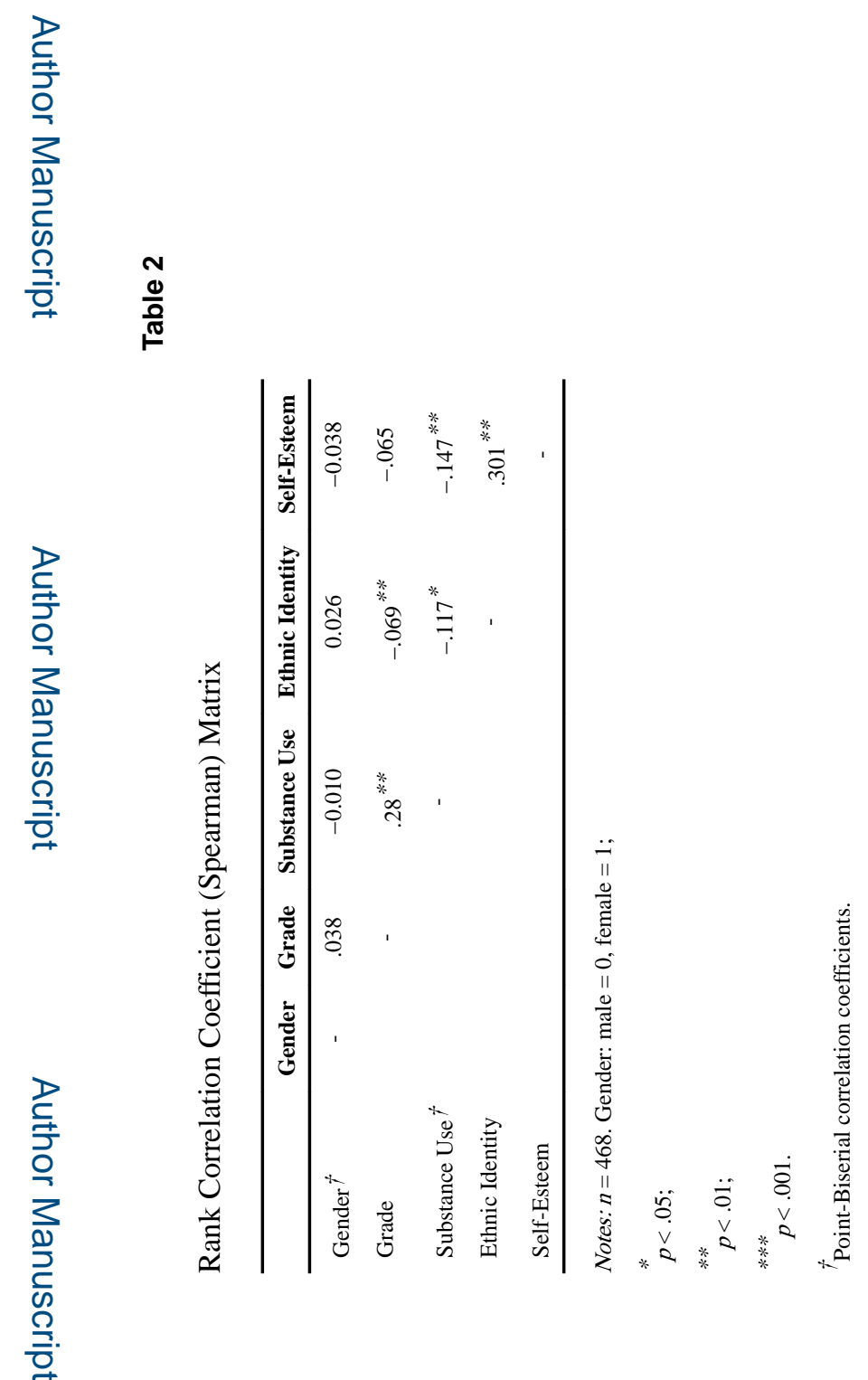

Addict Behav. Author manuscript; available in PMC 2018 April 05. 


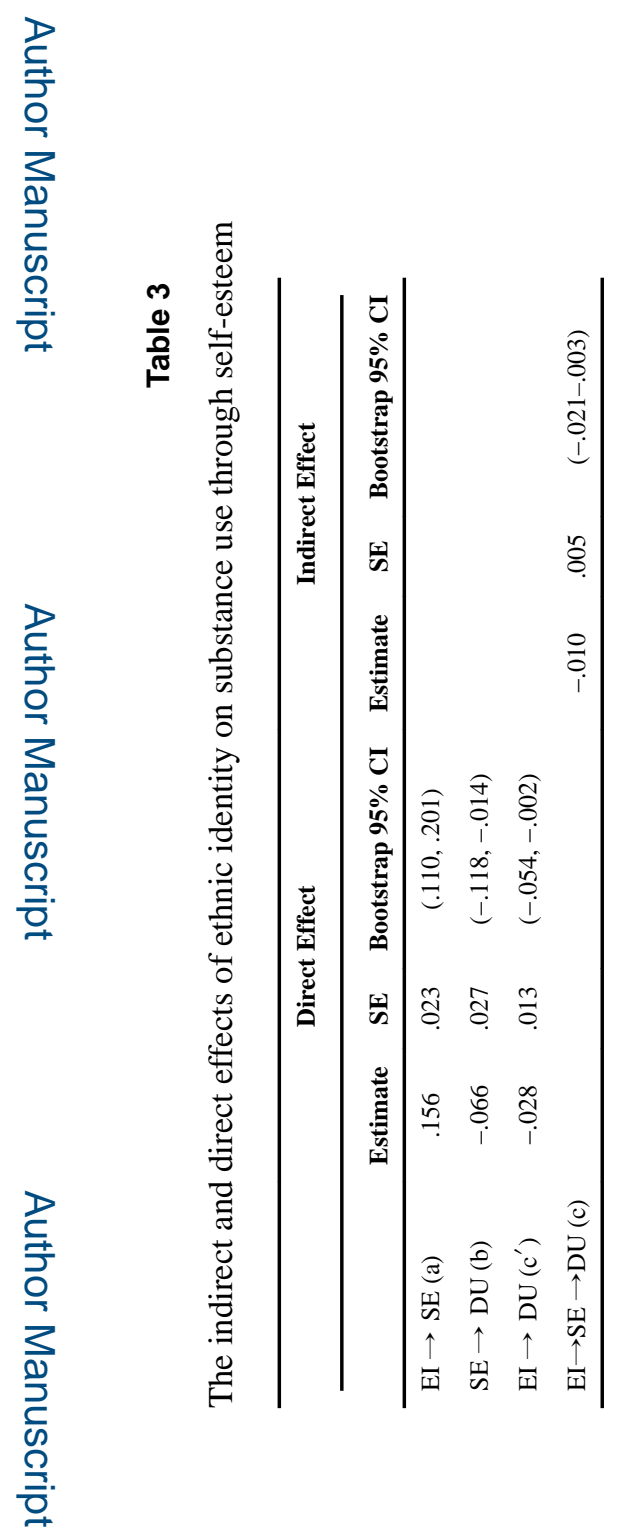

Addict Behav. Author manuscript; available in PMC 2018 April 05. 